\title{
Distinct genetic alteration profiles of acute myeloid leukemia between Caucasian and Eastern Asian population
}

\author{
Hui Wei', Ying Wang ${ }^{1}$, Chunlin Zhou', Dong Lin', Bingcheng Liu', Kaiqi Liu', Shaowei Qiu', Benfa Gong ${ }^{1}$, Yan Li ${ }^{1}$, \\ Guangji Zhang ${ }^{1}$, Shuning Wei ${ }^{1}$, Xiaoyuan Gong ${ }^{1}$, Yuntao Liu', Xingli Zhao', Runxia Gu', Yingchang Mi \\ and Jianxiang Wang ${ }^{1,2^{*}}$
}

\begin{abstract}
Racial and ethnic disparities in malignancies attract extensive attention. To investigate whether there are racial and ethnic disparities in genetic alteration between Caucasian and Eastern Asian population, data from several prospective AML trials were retrospectively analyzed in this study. We found that there were more patients with core binding factor (CBF) leukemia in Eastern Asian cohorts and there were different CBF leukemia constitutions between them. The ratios of CBF leukemia are 27.7, 22.1, 21.1, and 23.4\%, respectively, in our (ChiCTR-TRC-10001202), another Chinese, Korean, and Japanese Eastern Asian cohorts, which are significantly higher than those in ECOG1900, MRC AML15, UK NCRI AML17, HOVON/SAKK AML-42, and German AML2003 (15.5, 12.5, 9.3, 10.2, and 12\%, respectively). And CBFbeta-MYH1 1 occurred more prevalently in HOVON/SAKK AML- 42 and ECOG1900 trials (50.0 and 54.3\% of CBF leukemia, respectively) than in Chinese and Japanese trials (20.1 and 20.8\%, respectively). The proportion of FLT3-ITD mutation is $11.2 \%$ in our cohort, which is lower than that in MRC AML15 and UK NCRI AML17 (24.6 and 17.9\%, respectively). Even after excluding the age bias, there are still different incidence rates of mutation between Caucasian and Eastern Asian population. These data suggest that there are racial and ethnic disparities in genetic alteration between Caucasian and Eastern Asian population.
\end{abstract}

Keywords: Acute myeloid leukemia, Mutation, Core binding factor, FLT3-ITD

Acquired genetic abnormalities play an essential role in leukemogenesis and are one of the most important prognostic factors in acute myeloid leukemia (AML). To investigate whether there are some distinctions in genetic alteration profiles among different human races, data from several prospective AML trials were retrospectively analyzed. The ratio of core binding factor (CBF) leukemia in our cohort (ChiCTR-TRC-10001202) is 27.7\%. Similarly, the ratios are 22.1, 21.1, and 23.4\%, respectively, from Chinese, Korean, and Japanese, the other three Eastern Asian AML cohorts [1-3]. However, the CBF leukemia

\footnotetext{
* Correspondence: wangjx@ihcams.ac.cn

'Leukemia Center, Institute of Hematology and Blood Diseases Hospital, Chinese Academy of Medical Sciences \& Peking Union Medical College, Tianjin 300020, China

${ }^{2}$ State Key Laboratory of Experimental Hematology, Institute of Hematology and Blood Diseases Hospital, Chinese Academy of Medical Sciences and Peking Union Medical College, 288 Nanjing Road, Tianjin 300020, People's Republic of China
}

constitutes $15.5,12.5,9.3,10.2$, and $12 \%$ of patients, respectively, in ECOG1900, MRC AML15, UK NCRI AML17, HOVON/SAKK AML-42, and German AML 2003(Additional file 1: Table S1) [4-8]. All of the latter cohorts are from European or American countries. Therefore, CBF leukemia occurs more frequently in Eastern Asian countries than in European and American countries. Meanwhile, the proportion of NPM1 is 15.9 and 13.3\%, respectively, in our cohort and another Chinese one [3] (Additional file 1: Table S2). The proportions of FLT3-ITD mutation are 11.2 and $13.0 \%$, respectively, in our cohort and another Chinese one [3] (Additional file 1: Table S3). Whereas, NPM1 mutation ratios are 27.9, 29.0, and 33.0\%, respectively, in MRC AML15, UK NCRI AML17, and German AML2003. FLT3-ITD mutation occurs at 24.6 and $17.9 \%$, respectively, in MRC AML15 and UK NCRI AML17 (Additional file 1: Table S2 and S3) [5, 6, 8]. These data demonstrate that NPM1 and FLT3-ITD mutations are 
Table 1 Molecular mutation ratios of patients younger than 40 years old in MRC AML10 and AML12 and our cohort

\begin{tabular}{|c|c|c|c|c|c|c|c|c|c|}
\hline & MRC AML10 and & AML12 & & & China $1^{a}$ & & & & \\
\hline & Age range, years & MUT, no. & WT, No. & MUT/total, $\%$ & Median age (range), years & MUT, no. & WT, No. & MUT/total, \% & $\begin{array}{l}\text { (MRC } \\
\text { Vs. } \\
\text { China1) }\end{array}$ \\
\hline FLT3-ITD [9] & $15-34$ & 68 & 222 & 23.4 & $36(15-55)$ & 66 & 522 & 11.2 & $<0.001$ \\
\hline FLT3-TKD [10] & $15-39$ & 46 & 412 & 10.0 & $36(15-55)$ & 51 & 534 & 8.72 & 0.464 \\
\hline DNMT3a [11] & $15-39$ & 71 & 287 & 19.8 & $36(15-55)$ & 38 & 348 & 9.84 & $<0.001$ \\
\hline CEBPA [12] & $15-39$ & 49 & 524 & 8.6 & $36(15-55)$ & 116 & 442 & 20.8 & $<0.001$ \\
\hline CEBPA double [12] & $15-39$ & 33 & 540 & 5.8 & $36(15-55)$ & 75 & 483 & 13.4 & $<0.001$ \\
\hline CEBPA single [12] & $15-39$ & 16 & 557 & 2.9 & $36(15-55)$ & 41 & 517 & 7.3 & $<0.001$ \\
\hline
\end{tabular}

Abbreviations: WT wild type, MUT Mutant

${ }^{\text {ab }}$ ata from our cohort (ChiCTR-TRC-10001202)

less common in Chinese AML patients in comparison with cases from Europe. It indicates that there are some differences in the frequencies of genetic alteration between Caucasian and Eastern Asian population.

The bias of these comparisons result from the fact that patients from Chinese and Korean cohorts are younger than those from European and American cohorts. To eliminate this bias, we only compared the molecular mutation constitution from patients younger than who were 40 years old in MRC AML10 and AML12 [9-12]. As shown in Table 1, all of the molecular mutations, except FLT3-TKD, are significantly different between MRC cohorts and ours. After excluding the age bias, the ratio of FLT3-ITD mutation is still higher in MRC cohorts, which is similar to the results based on the entire cohorts. And there are more DNMT3a mutations and less CEBPA mutations in MRC cohorts.

In order to further confirm that these differences were not due to the onset of age, we analyzed the data in patients older than 40 or 50 years old from Chinese and Japanese trials and compared with Caucasian data. As shown in Additional file 1: Table S4, the frequency of FLT3-ITD in patients older than 40 years old from Chinese trial is only $11.5 \%$ which is still significantly lower than that in MRC AML15 and UK NCRI
AML17 trial (24.6 and $17.9 \%$, respectively) $[5,6]$. There are 24.4 and $18.7 \%$ CBF leukemia in patients older than 40 or 50 years old of Chinese and Japanese trials, respectively. They are all significantly higher than those from Caucasian trials, except that the difference between Japanese trials and ECOG1900 did not reach the threshold of statistical significance (Additional file 1: Table S5). NPM1 mutation occurs in $23.6 \%$ patients older than 40 years old from Chinese trial. It is still lower than Caucasian data, although there is only statistically difference in comparison with German AML2003 ( $P=0.005)$ (Additional file 1: Table S6). These data suggest that AML patients older than 40 years old still had distinctions in frequencies of CBF and FLT3ITD alterations, which is similar to the difference among the entire cohorts.

As we know, CBF alteration comprises CBFbetaMYH11 and AML1-ETO fusion genes. Therefore, we finally compared and contrasted the CBF leukemia constitution between Eastern Asian and Caucasian trials. As shown in Table 2, CBFbeta-MYH11 occurred in 50.0 and $54.3 \%$ of CBF leukemia in HOVON/SAKK AML- 42 and ECOG1900 trials, respectively [4, 7]. There are only 20.1 and $20.8 \%$ CBFbeta-MYH11 in Chinese and Japanese trials, respectively [13], which are significantly lower than Caucasian data. We also

Table 2 CBF leukemia constitution in Japanese and Chinese cohorts against European and American cohorts

\begin{tabular}{|c|c|c|c|c|c|c|}
\hline & ${\text { China } 1^{a}}$ & $\begin{array}{l}\text { JALSG AML95, 97, and } 201 \\
\text { [13] }\end{array}$ & ${\text { China } 1^{a}}$ & $\begin{array}{l}\text { JALSG AML95, 97, and } 201 \\
\text { [13] }\end{array}$ & $\begin{array}{l}\text { HOVON/SAKK AML- } 42 \\
\text { [7] }\end{array}$ & $\begin{array}{l}\text { ECOG1900 } \\
{[4]}\end{array}$ \\
\hline Median age, years & 36 & - & 46 & - & 49 & 48 \\
\hline Age range, years & $15-55$ & $15-64$ & $40-55$ & $50-64$ & $17-60$ & $17-60$ \\
\hline CBFß-MYH11, no. & 33 & 107 & 15 & 34 & 44 & 57 \\
\hline AML1-ETO, no. & 131 & 408 & 43 & 134 & 44 & 48 \\
\hline CBFß-MYH11 in CBF (\%) & 20.1 & 20.8 & 25.9 & 20.2 & 50.0 & 54.3 \\
\hline$P$ value (vs. ECOG1900) & $<0.001$ & $<0.001$ & $<0.001$ & $<0.001$ & 0.553 & \\
\hline $\begin{array}{l}P \text { value (vs. HOVON/SAKK } \\
\text { AML- } 42 \text { ) }\end{array}$ & $<0.001$ & $<0.001$ & 0.004 & $<0.001$ & & 0.553 \\
\hline
\end{tabular}

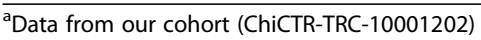


calculated the frequencies in older patients in Eastern Asian trials. The CBFbeta-MYH11 ratios are 25.9 and $20.2 \%$ in AML patients older than 40 or 50 years old in Chinese and Japanese trials, respectively, which are also significantly lower than that in $\mathrm{HOVON} / \mathrm{SAKK}$ AML- 42 and ECOG1900 trials and similar to the results of the entire cohort analysis (Table 2). These data indicate that both CBF leukemia frequencies and CBF leukemia constitutions are distinct between Eastern Asian and Caucasian trials, not only in the entire cohorts but also in post hoc analysis after excluding the age bias. We followed the outcome of all these cohorts after we found different mutation landscape. But we only showed, but did not compare the outcome between these cohorts since it is too complicated to compare the outcomes when patients received different therapies (Additional file 1: Table S7).

All these data indicate that the different incidence of patterns of mutation acquisition exists between Caucasian and Eastern Asian population, suggesting that genetic backgrounds have an impact on leukemogenesis. We think that these differences become more and more important and are needed to be further investigated, since many novel drugs, such as FLT3 and IDH2 inhibitors, target on genetic mutations and the effectiveness may depend on patterns of mutation acquisition.

\section{Additional files}

Additional file 1: This file contains Tables S1-S7, including Table S1. CBF ratios in European, American, and Eastern Asian cohorts; Table S2. NPM1 mutation ratios in European and our cohorts; Table S3. FLT3-ITD mutation ratios in European and our cohorts; Table S4. FLT3-ITD mutation ratios in older patients from Chinese cohort against European and American cohorts; Table S5. CBF leukemia ratios in older patients from Japanese and Chinese cohorts against European and American cohorts; Table S6. NPM1 mutation ratios in older patients from Chinese cohort against European and American cohorts; and Table S7. Outcomes in European, American, and Eastern Asian cohorts. (PDF 568 kb)

\section{Abbreviations}

AML: Acute myeloid leukemia; CBF: Core binding factor; MUT: Mutant; WT: Wild type

\section{Acknowledgements}

Not applicable.

\section{Funding}

This study was supported by State Key Program of National Natural Science Foundation of China (81430004), Foundation for Innovative Research Groups of the National Natural Science Foundation of China (81421002), National Natural Science Foundation of China (81670159), and CAMS Innovation Fund for Medical Sciences (CIFMS 2016-12M-1-001, 2016-12M-3-004).

\section{Availability of data and materials}

The data used and/or analyzed during the current study are available from the corresponding author on reasonable request.

\section{Authors' contributions}

Hui Wei and JianxiangWang designed and performed the experiments, analyzed the data, and wrote the paper. Yingchang Mi provided comments on writing the paper. All authors contributed to the interpretation of the results. All authors read and approved the final manuscript.

\section{Ethics approval and consent to participate}

The data about the patients were used after obtaining approval by the ethical committee of Institute of Hematology and Blood Diseases Hospital, CAMS \& PUMC.

\section{Consent for publication}

Not applicable.

\section{Competing interests}

The authors declare that they have no competing interests.

\section{Publisher's Note}

Springer Nature remains neutral with regard to jurisdictional claims in published maps and institutional affiliations.

Received: 15 December 2017 Accepted: 2 February 2018

Published online: 10 February 2018

\section{References}

1. Lee JH, Joo YD, Kim H, Bae SH, Kim MK, Zang DY, Lee JL, Lee GW, Lee JH, ParkJH, Kim DY, Lee WS, Ryoo HM, Hyun MS, Kim HJ, Min YJ, Jang YE, Lee $\mathrm{KH}$; Cooperative Study Group A for Hematology. A randomized trial comparing standard versus high-dose daunorubicin induction in patients with acute myeloid leukemia. Blood. 2011;118(14):3832-3841.

2. Ohtake S, Miyawaki S, Fujita H, Kiyoi H, Shinagawa K, Usui N, Okumura H, Miyamura K, Nakaseko C, Miyazaki Y, Fujieda A, Nagai T, Yamane T, Taniwaki M, Takahashi M, Yagasaki F, Kimura Y, Asou N, Sakamaki H, Handa H, Honda S, Ohnishi K, Naoe T, Ohno R. Randomized study of induction therapy comparing standard-dose idarubicin with high-dose daunorubicin in adult patients with previously untreated acute myeloid leukemia: the JALSG AML201 Study. Blood. 2011;117(8):2358-65.

3. Jin J, Wang JX, Chen FF, Wu DP, Hu J, Zhou JF, Hu JD, Wang JM, Li JY, Huang XJ, Ma J, Ji CY, Xu XP, Yu K, Ren HY, Zhou YH, Tong Y, Lou YJ, Ni WM, Tong HY, Wang HF, Mi YC, Du X, Chen BA, Shen Y, Chen Z, Chen SJ. Homoharringtonine-based induction regimens for patients with de-novo acute myeloid leukaemia: amulticentre, open-label, randomised, controlled phase 3 trial. Lancet Oncol. 2013;14(7):599-608.

4. Fernandez HF, Sun Z, Yao X, Litzow MR, Luger SM, Paietta EM, Racevskis J, Dewald GW, Ketterling RP, Bennett JM, Rowe JM, Lazarus HM, Tallman MS. Anthracycline dose intensification in acute myeloid leukemia. N Engl J Med. 2009;361(13):1249-59.

5. Burnett AK, Russell NH, Hills RK, Hunter AE, Kjeldsen L, Yin J, Gibson BE, Wheatley K, Milligan D. Optimization of chemotherapy for younger patients with acute myeloid leukemia: results of the medical research council AML15 trial. J Clin Oncol. 2013;31(27):3360-8.

6. Burnett AK, Russell NH, Hills RK, Kell J, Cavenagh J, Kjeldsen L, McMullin MF,Cahalin P, Dennis M, Friis L, Thomas IF, Milligan D, Clark RE; UK NCRI AML Study Group. A randomized comparison of daunorubicin $90 \mathrm{mg} / \mathrm{m} 2$ vs $60 \mathrm{mg} / \mathrm{m} 2$ in AML induction: results from the UK NCRI AML17 trial in 1206 patients. Blood 2015;125(25):3878-3885

7. Löwenberg B, Pabst T, Vellenga E, van Putten W, Schouten HC, Graux C, Ferrant A, Sonneveld P, Biemond BJ, Gratwohl A, de Greef GE, Verdonck LF, Schaafsma MR,Gregor M, Theobald M, Schanz U, Maertens J, Ossenkoppele GJ; Dutch-Belgian Cooperative Trial Group for Hemato-Oncology (HOVON) and Swiss Group for Clinical Cancer Research (SAKK) Collaborative Group. Cytarabine dose for acute myeloid leukemia. N Engl J Med 2011;364(11): 1027-1036.

8. Schaich M, Parmentier S, Kramer M, Illmer T, Stölzel F, Röllig C, Thiede C, Hänel M, Schäfer-Eckart K, Aulitzky W, Einsele H, Ho AD, Serve H, Berdel WE, Mayer J, Schmitz N, Krause SW, Neubauer A, Baldus CD, Schetelig J, Bornhäuser M, Ehninger G. High-dose cytarabine consolidation with or without additional amsacrine and mitoxantrone in acute myeloid leukemia: results of the prospective randomized AML2003 trial. J Clin Oncol. 2013; 31(17):2094-102

9. Kottaridis PD, Gale RE, Frew ME, Harrison G, Langabeer SE, Belton AA, Walker $H$, Wheatley K, Bowen DT, Burnett AK, Goldstone AH, Linch DC. The presence of a FLT3 internal tandem duplication in patients with acute myeloid leukemia (AML) adds important prognostic information to 
cytogenetic risk group and response to the first cycle of chemotherapy: analysis of 854 patients from the United Kingdom Medical Research Council AML 10 and 12 trials. Blood. 2001;98(6):1752-9.

10. Mead AJ, Linch DC, Hills RK, Wheatley K, Burnett AK, Gale RE. FLT3 tyrosine kinase domain mutations are biologically distinct from and have a significantly more favorable prognosis than FLT3 internal tandem duplications in patients with acute myeloid leukemia. Blood. 2007;110(4):1262-70.

11. Gale RE, Lamb K, Allen C, El-Sharkawi D, Stowe C, Jenkinson S, Tinsley S, Dickson G, Burnett AK, Hills RK, Linch DC. Simpson's paradox and the impact of different DNMT3A mutations on outcome in younger adults with acute myeloid leukemia. J Clin Oncol. 2015;33(18):2072-83.

12. Green $\mathrm{CL}$, Koo KK, Hills RK, Burnett AK, Linch DC, Gale RE. Prognostic significance of CEBPA mutations in a large cohort of younger adult patients with acute myeloid leukemia: impact of double CEBPA mutations and the interaction withFLT3 and NPM1 mutations. J Clin Oncol. 2010;28(16):2739-47.

13. Yanada M, Ohtake S, Miyawaki S, Sakamaki H, Sakura T, Maeda T, Miyamura K, Asou N, Oh I, Miyatake J, Kanbayashi H, Takeuchi J, Takahashi M, Dobashi N, Kiyoi H, Miyazaki Y, Emi N, Kobayashi Y, Ohno R, Naoe T; Japan Adult Leukemia Study Group. The demarcation between younger and older acute myeloid leukemia patients: a pooled analysis of 3 prospective studies. Cancer 2013;119(18):3326-3333.

\section{Submit your next manuscript to BioMed Central and we will help you at every step:}

- We accept pre-submission inquiries

- Our selector tool helps you to find the most relevant journal

- We provide round the clock customer support

- Convenient online submission

- Thorough peer review

- Inclusion in PubMed and all major indexing services

- Maximum visibility for your research

Submit your manuscript at www.biomedcentral.com/submit 